\title{
Technical Efficiency Analysis of Agricultural Research and Development in Higher Educational Institutes of Pakistan
}

Hina Fatima

Ph.D scholar in Fatima Jinnah Women University, Rawalpindi, Pakistan

Nouman Badar

Pakistan Agricultural Research Council (PARC), Planning Division, Islamabad, Pakistan

Munib Badar

PhD Scholar IQRA University Islamabad

\begin{abstract}
The role of education is one of the fundamental factors of any country social and economic development. This epigrammatic present the general idea of the most important investment trends in agricultural research in Higher Education Institutes (HEI) in Pakistan since the early 2003 to 2009, The enhancement in higher education institutes in agriculture research around the world in those days suggests that the higher education institutes in Pakistan also should formulate superior involvement to overall agriculture R\&D. Data envelopment Analysis (DEA) instrument is used in order to assess the technical efficiency of 23 HEI of Pakistan. The technical and scale efficiency results suggests the agricultural universities in Pakistan are functioning at a fairly high level of efficiency, although there is room for improvement in several universities by improving the efficiency of those $\mathrm{HEI}$, in order to operate at optimal scale.
\end{abstract}

Keywords: Higher Education Institutes (HEI), technical efficiency and scale efficiency

\section{INTRODUCTION}

The Agriculture sector continues to play a fundamental position in Pakistan's economy. It is the second largest sector, accounting for over 21 percent of GDP, and remains by far the largest employer, absorbing 45 percent of the country's total labor force. Nearly 62 percent of the country's population resides in rural areas, and is directly or indirectly linked with agriculture for their livelihood (GOP, 2011). Pakistan being an agricultural developing country has to produce more output in all obedience of agriculture. By way of required revolutionize in the structure of the agricultural investment. The food price and economic crisis in 2008 have had a severe impact

on majority of people in Pakistan. The solution to long-term food security lies in augmenting investment in agriculture research and development. There is no doubt about that socio economic status, poverty, political instability, terrorism, macro and microeconomic policies breakdown and gigantic drop in foreign direct investment play a critical constancy in lowering Pakistan economic growth. But above all the role of education is one of the fundamental factors of any country social and economic development. Later than the independence of Pakistan in 1947, there was about 10\% literacy rate. Miscellaneous Government set several targets during their tenure to hoist the literacy rate; current Government also set a target about 85\% literacy rates till 2015. We can't disregard the significant role of education towards escorting economic growth, various studies like [afzal et al. (2010); Martin and Barro (1995); Barro and Martin (1997); Barro (1991)] gives us an idea about the positive correlation in between education and economic growth. Growth theories by [Romer (1986); Romer (1987); Lucas (1988); Barro (1990)] provided the central idea about the relationship and Lucas (1988) in their endogenous growth models presented a fundamental initiative regarding role of education in the economic growth, and then various other studies by [Nili and Nafisi (2003); Gadiri and Dargahi (2003); Emadzadeh et al.(2000)] also estimate the consequences of education towards economic growth, and that found positive and significant association between them. 
Hina Fatima et al. "Technical Efficiency Analysis of Agricultural Research and Development in Higher Educational Institutes of Pakistan"

(Laghari 2012) "identified the various challenges in Pakistan education and research network include access to higher education enrollment and equity, quality and standard of education, faculty, and research, and significance of research in universities building it plays vital role in the building of Economies, Communities and Leadership. According to him education enrollment of Turkey, Malaysia, China, Indonesia and India is ten times more than Pakistan's"1.

In this regard higher education institutes (HEI) role is quite noteworthy in determining agriculture sector of Pakistan multidimensional through further research and investment in diverse fields of agriculture. Being a agricultural country development in agriculture sector result in reducing poverty, upgrading in socioeconomic status of $62 \%$ of people that living in rural area and as well as development of whole of nation also. More enrollment rates in higher education institutes related to agriculture research and development result in promoting efficient labor, human capital, magnetize investment and transforming more advancement in agriculture sector and economic growth. Subsequently, it also shows the way to earn more foreign exchange.

\section{Objectives of the Study}

- To estimate technical efficiency of HEI towards agricultural research and development production in Pakistan.

- To estimate returns to scale in HEI in Agricultural R\&D.

\section{LITERATURE REVIEW}

The enhancement in higher education institutes in agriculture research around the world in those days suggests that the higher education institutes in Pakistan also should formulate superior involvement to overall agriculture $R \& D$. One key element of this literature narrates to the compilation and study of data. Various studies [Anderson (1991); Roseboom et al. (1991), Evenson (2003), Peterson and Perrault (1998); Fischer and Byerlee (2002) Fuglie Pray (2001), coelli and Rao (2003)] examined the role of public investment in agriculture R\&D as well as the performance of agriculture research institutes and share of private sector in agriculture R\&D. Further studies of [Avkiran (2001); Johnes (2006); Johnes and Yu (2008); Kuah et al. (2011); Bougnol et al. (2006); Flegg et al. (2004)] evaluated the contribution of Higher education institutes towards investment and interventions in R\&D.

Johnes (2006) apply Data envelopment analysis (DEA) to 2547 Economics graduates from UK Universities in 1993 in order to assess teaching efficiency. Each individual's efficiency is decomposed into two components: one attributable to the university at which the student studied and the other attributable to the student himself. The results suggest that efficiencies derived from DEAs performed at an aggregate level are misleading because it includes both institution and individual components. Johnes and Yu (2008) examine the relative efficiency in the production of research of 109 Chinese regular universities in 2003 and 2004. Output variables measure the impact and productivity of research; input variables reflect staff, students, capital and resources. Mean efficiency is just over $90 \%$ when all input and output variables are included in the model, and this falls to just over $80 \%$ when student-related input variables are excluded from the model. The rankings of the universities across models and time periods are highly significantly correlated. Kuah et al. (2011) examine the relative teaching and research efficiencies of universities. The model was tested using a hypothetical example and its use and implications in university performance measurement were described. The application of DEA enables academics to identify deficient activities in their universities and take appropriate actions for improvement.

Bougnol et al. (2006) evaluate two classification and ranking schemes concerning universities; one from a published report, "Top American Research Universities" by the University of Florida's The Center and the other using DEA. This suggests that DEA is a suitable tool for these types of studies. Johnes (2006) study the possibility of measuring efficiency in the context of higher education. The paper ends with an application of DEA to a data set of more than 100 Health education institutions in England using data for the year 2000/01. Technical and scale efficiency are high on average in the English higher education sector.

\footnotetext{
${ }^{1}$ Dr. Javed Laghari is Chairman of HEC, this statement he given in a press release at the Institute of Strategic Studies Islamabad (ISSI) organized a Public talk on 27th July 2011.
} 
Hina Fatima et al. "Technical Efficiency Analysis of Agricultural Research and Development in Higher Educational Institutes of Pakistan"

Flegg et al. (2004) study the technical efficiency (TE) of 45 British universities in the period 1981 to 1993. To show the causes of variations in efficiency, TE is decomposed into pure technical, congestion and scale efficiency. The analysis of the study shows that there was a substantial rise in the weighted geometric mean TE score during the study period, although this rise was most noticeable between 1988 and 1991. Avkiran (2001) apply data envelopment analysis (DEA) to scrutinize the relative efficiency of Australian universities. In this regard he develops three models, namely, overall performance, performance on delivery of educational services, and performance on fee-paying enrolments. The finding explains that university sector was performing well on technical and scale efficiency but the gap of improving performance on fee-paying enrolments exist. Abbott and Doucouliagos (2003) use non-parametric techniques to estimate technical and scale efficiency of individual Australian universities. The finding expresses that in spite of the output input mix, Australian universities as whole recorded high levels of efficiency relative to each other. Results of the previous studies suggests that overall mean research efficiency is higher in educations universities is higher and performing quite well in $\mathrm{R} \& \mathrm{D}$.

\section{DATA AND METHODOLOGY}

This epigrammatic present the general idea of the most important investment trends in agricultural research in Higher Education Institutes (HEI) in Pakistan since the early 2003 to 2009, description of a latest set of data developed all the way through a comprehensive survey.

The level of technical efficiency of a particular firm is characterized by the relationship between observed production and some ideal or potential production (Greene, 1993). The measurement of firm specific technical efficiency is based upon deviations of observed output from the best production or efficient production frontier. If a firm's actual production point lies on the frontier it is perfectly efficient. If it lies below the frontier then it is technically inefficient, with the ratio of the actual to potential production defining the level of efficiency of the individual firm (Farrell, 1957).

In present study we utilized data envelopment analysis (DEA) approach to measure the technical efficiency of HEI related to agricultural R\&D. DEA (data envelopment analysis) which is nonparametric approach involve linear programming and does not impose any functional form restrictions, as DEA is a non-parametric approach, so works under the assumption of no random shocks in the data set. In this paper we applied the Data Envelopment Analysis (DEA) instrument in order to assess the technical efficiency of $23 \mathrm{HEI}^{2}$ of Pakistan.

The following input and output variables are used in the DEA analysis:

Input Variables

- $\quad$ The number of Ph.D. staff;

- The number of MS/M.Phil. staff

- The number of MSC/BS staff; and

- The number of admin staff

- The number of technical staff

\section{Output Variables}

- The number of Ph.D. graduates

- The number of MS/MPhil graduates

- The number of BS graduate.

The present study uses a single-step methodology. In the first step, data envelopment analysis (DEA) is used to model efficiencies as an explicit function of discretionary variables. The methodology is specified below.

"Assuming we have data on $K$ inputs and $M$ outputs of $\mathrm{N}$ years, $\mathrm{x}_{\mathrm{i}}$ is an input vector for the $\mathrm{i}^{\text {th }}$ farm and $\mathrm{y}_{\mathrm{i}}$ is an output vector for the $\mathrm{i}^{\text {th }}$ year. The $\mathrm{K} \times \mathrm{N}$ input matrix, $X$, and $\mathrm{M} \times \mathrm{N}$ output matrix, $Y$, represent the data of all HEI institions N. For each institute, we obtained a measure of the ratio of all

\footnotetext{
${ }^{2}$ List of 23 institutes provided in appendix
} 
Hina Fatima et al. "Technical Efficiency Analysis of Agricultural Research and Development in Higher Educational Institutes of Pakistan"

outputs over all inputs, such as $\mathrm{u} / \mathrm{y}_{\mathrm{i}} / \mathrm{v} / \mathrm{x}_{\mathrm{i}}$, where $\mathrm{u}$ is an $\mathrm{M} * 1$ vector of output weights and $\mathrm{v}$ is $\mathrm{K} * 1$ vector of input weights. To select optimal weights we solve the mathematical programming problem as specified by Coelli, et al (1998)". Firstly,

$\max _{\mathrm{u}, \mathrm{v}}\left(\mathrm{u} / \mathrm{y}_{\mathrm{i}} / \mathrm{v} / \mathrm{x}_{\mathrm{i}}\right)$

subject to

$$
\begin{gathered}
u / y_{j} / v / x_{j} \leq 1, j=1,2, \ldots \ldots N, \\
u, v \geq 0
\end{gathered}
$$

$\max _{\mathrm{u}, \mathrm{v}}\left(\mathrm{u} / \mathrm{y}_{\mathrm{i}} / \mathrm{v} / \mathrm{x}_{\mathrm{i}}\right)$

Subject to

$$
\begin{gathered}
V / x_{i}=1 \\
u / y_{j} / v / x_{j} \leq 1, j=1,2, \ldots \ldots N, \\
u, v \geq 0
\end{gathered}
$$

Secondly,

$\operatorname{Min}_{\theta}, \lambda \theta$

$$
\begin{gathered}
-y_{i}+Y \lambda \geq 0 \\
\theta x_{i}-X \lambda \geq 0 \\
\lambda \geq 0
\end{gathered}
$$

Where, $\theta=$ is a scalar, Restriction: $\theta \leq 1, \lambda=$ is a Nx1 vector of constants

Coelli, et al (1998) "suggest that a constant returns to scale DEA model is only appropriate when all firms are operating at an optimal scale, this is not possible in agriculture due to many constraints such as imperfect competition and financial constraints, etc. Bankers, et al. (1984) modifies the constant returns to scale DEA model into a variable returns to scale model by adding convexity constraints". Variable Returns to Scale (VRS) DEA model is also found in detail in the studies; Ferrier, D. and Lovell C, A. K., (1990), and Sharma et. al., 1999. Following Coelli, et al (1998), an input-oriented variable returns to scale DEA model will be used to estimate technical efficiency. Here, the objective is to determine the relative efficiency for each year. Efficiency is measured by the ratio of inputs to outputs as follows:

$\operatorname{Min}_{\theta}, \lambda \theta$,

Subject to

$$
\begin{gathered}
-y_{i}+Y \lambda \geq 0 \\
x_{i}-X \lambda \geq 0 \\
N 1 / \lambda=1 \\
\lambda \geq 0
\end{gathered}
$$

Where, N1/ $\lambda=1$ represents a convexity constraint which ensures that an inefficient HEI is only benchmarked against institute of a similar size. $Y$ represents the output matrix for $\mathrm{N}$ year. $\theta$ represents the total technical efficiency of the ith HEI. $\lambda$ represents $\mathrm{N}$ x 1 constants. $X$ represents the input matrix for $\mathrm{N}$ year HEI.

While in variable return to scale Data Envelopment Analysis we use the term pure technical efficiency because it is free from scale effects. DEA more flexible in case of variable return to scale and CRS and VRS carried out on the same data set. The ratio between CRS and VRS technical efficiency scores is called scale efficiency. A decision making unit is called scale efficient if VRS and CRS, technical efficiency score are equal.

\section{RESULT AND DISCUSSION}

Descriptive Analysis

Descriptive analysis for input and output variables of HEI are presented in Table.1 (see Appendix). Descriptive statistics of enrolled students shows that percentage change in PhDs, MS, and MSC/BS in year 2003 was about $17 \%, 10.1 \%$ and $10 \%$, respectively. Percentage change in in case of PhDs, MS 
Hina Fatima et al. "Technical Efficiency Analysis of Agricultural Research and Development in Higher Educational Institutes of Pakistan"

and MSC. Staff was about 11.8\%, 10.9\% and 15\%, respectively. In case of graduated students of $\mathrm{PhDs}$, MS and MSc/BS the percentage change was about $2.9 \%, 10.4 \%$ and $11.9 \%$, respectively.

In year 2004 descriptive statistics of enrolled students shows that percentage change in PhDs, MS, and MSC/BS was about $12.8 \%, 14.5 \%$ and $11.1 \%$, respectively. Percentage change in case of PhDs, MS and MSC Staff was about $12.2 \%, 11.7 \%$ and $11 \%$, respectively. In case of graduated students of $\mathrm{PhDs}$, MS and MSc/BS the percentage change was about 3.7\%, $11 \%$ and $14.2 \%$, respectively. In year 2005 descriptive statistics of enrolled students shows that percentage change in $\mathrm{PhDs}$, MS, and MSC/BS was about $11.3 \%, 11 \%$ and $12.8 \%$, respectively. The percentage changes in case of PhDs, MS and MSC. Staff was about $13 \%, 12.2 \%$ and $12.3 \%$, respectively. In case of graduated students of $\mathrm{PhDs}, \mathrm{MS}$ and $\mathrm{MSc} / \mathrm{BS}$ the percentage change was about $4.4 \%, 16.5 \%$ and $13.2 \%$, respectively.

In year 2006 descriptive statistics of enrolled students shows that percentage change in PhDs, MS, and MSC/BS it was about $13.8 \%, 11.5 \%$ and $12.9 \%$, respectively. The percentage changes in case of PhDs, MS and MSC Staff was about $13.9 \%, 13.8 \%$ and $13.8 \%$, respectively. In case of graduated students of PhDs, MS and MSc/BS the percentage change was about $13.5 \%, 12.5 \%$ and $13.1 \%$, respectively. In year 2007 descriptive statistics of enrolled students shows that percentage change in $\mathrm{PhDs}$, MS, and MSC/BS was about 19\%, 23.7\% and 14.6\% respectively. The percentage changes in case of PhDs, MS and MSC. Staff was about $15.1 \%, 14.7 \%$ and $15.7 \%$, respectively. In case of graduated students of PhDs, MS and MSc/BS the percentage change was about $6.3 \%, 15.5 \%$ and $16.6 \%$, respectively. In year 2008 descriptive statistics of enrolled students shows that percentage change in $\mathrm{PhDs}$, MS, and MSC/BS was about $11.3 \%, 10.5 \%$ and $22 \%$, respectively. The percentage changes in case of PhDs, MS and MSC Staff was about16.5\%, 17.7\% and 15.6\%, respectively. In case of graduated students of PhDs, MS and MSc/BS the percentage change was about $72.7 \%, 26.1 \%$ and $17.7 \%$, respectively.

In year 2009 descriptive statistics of enrolled students shows that percentage change in PhDs, MS, and MSC/BS was about $14.8 \%, 18.6 \%$ and $16.7 \%$, respectively. The percentage changes in case of $\mathrm{PhDs}$, MS and MSC. Staff was about $17.5 \%, 18.9 \%$ and $16.3 \%$, respectively. In case of graduated students of PhDs, MS and MSc/BS the percentage change was about $6.4 \%, 8.1 \%$ and $13.2 \%$, respectively. There is a significant difference between the percentages of all the variables, precisely, the input and output variables are all higher, on average, for HEIs from 2003-2009. The descriptive analysis shows the increasing trend with each passing year in agricultural research and development.

\section{Empirical Analysis}

The result of the study shows that Pakistan HEI related to Agriculture R\&D is overall, technical and scale efficient. The use of DEA to universities technical efficiency analysis has largely focused on the efficiencies of university departments related to agriculture research and development. Through literature review it should be quite that for scholastic application there is no definite research work that assistance us for the selection of input and outputs.

Table 4.1

\begin{tabular}{|l|l|l|l|}
\hline \multicolumn{2}{|c|}{ On Average Technical efficiency of HEC Institutes in Agriculture (R\&D) from (2003-09) } \\
\hline Year & \multicolumn{1}{|c|}{ CRSTE } & \multicolumn{1}{c|}{ SE } \\
\hline $\mathbf{2 0 0 3}$ & 0.899 & 0.978 & 0.922 \\
\hline $\mathbf{2 0 0 4}$ & 0.932 & 0.971 & 0.957 \\
\hline $\mathbf{2 0 0 5}$ & 0.926 & 0.987 & 0.938 \\
\hline $\mathbf{2 0 0 6}$ & 0.955 & 0.972 & 0.978 \\
\hline $\mathbf{2 0 0 7}$ & 0.966 & 0.984 & 0.981 \\
\hline $\mathbf{2 0 0 8}$ & 0.876 & 0.975 & 0.901 \\
\hline $\mathbf{2 0 0 9}$ & 0.901 & 0.921 & 0.974 \\
\hline
\end{tabular}

A swift of the efficiency scores for all HEI is presented in Table 4.1. Results show that there was a fewer amount of deviation of efficiency scores from the best practice frontier. The mean variable return to scale technical efficiency (VRSTS) score of HEI in year 2003 scores was about 0.978. The average VRSTE score suggests that the average inputs for the HEI could be possibly reduced by $2.2 \%$ without upsetting the level of outputs. On the other hand the overall scale efficiency of HEI in year 2003 was about 0.92 that depicts that HEI scale efficiency was less than unity, so HEI were not scale efficient in year 2003 
Hina Fatima et al. "Technical Efficiency Analysis of Agricultural Research and Development in Higher Educational Institutes of Pakistan"

An analysis of VRSTE in year 2004 revealed that the mean technical efficiency in year 2004 was about 0.97 . So on average there was possibility to reduced inputs about $3 \%$ in HEI without affecting the output. On average the scale efficiency in year 2004 was about 0.95 , so under the assumption of variable return to scale the HEI could save on average $5 \%$ of their inputs if they operate on optimal scale.

The result of the study shows that in year 2005 the mean technical efficiency of HEI was about 0.987 . On average there was possibility to reduced inputs about $1.3 \%$ in HEI without affecting the output. . The scale efficiency in year 2005 was about 0.93 , so there is possibility to save about $7 \%$ of input in HEI, and operate at optimal scale.

The mean variable return to scale technical efficiency (VRSTS) score of HEI in year 2006 scores was about 0.972 . The average VRSTE score suggests that the average inputs for the HEI could be possibly reduced by $2.8 \%$ without upsetting the level of outputs. On the other hand the overall scale efficiency of HEI in year 2006 was about 0.978 that depicts that HEI scale efficiency was less than unity, so HEI were not scale efficient in year 2006.

The mean variable return to scale technical efficiency (VRSTS) score of HEI in year 2007 scores was about 0.984 . The average VRSTE score suggests that the average inputs for the HEI could be possibly reduced by $1.6 \%$ without disturbing the level of outputs. On the other hand the overall scale efficiency of HEI in year 2006 was about 0.981 that describes that HEI scale efficiency was less than unity, so HEI were not scale efficient in year 2007.

The mean variable return to scale technical efficiency (VRSTS) score of HEI in year 2008 scores was about 0.975 . The average VRSTE score suggests that the average inputs for the HEI could be possibly reduced by $2.5 \%$ without distressing the level of outputs. On the other hand the overall scale efficiency of HEI in year 2008 was about 0.901 that portrays that HEI scale efficiency was less than unity, so HEI were not scale efficient in year 2008.

The mean variable return to scale technical efficiency (VRSTS) score of HEI in year 2009 scores was about 0.921 . The average VRSTE score suggests that the average inputs for the HEI could be possibly reduced by $8 \%$ without troubling the level of outputs. On the other hand the overall scale efficiency of HEI in year 2009 was about 0.974 that represents that HEI scale efficiency was less than unity, so HEI were not scale efficient in year 2009.

Table 4.2

\begin{tabular}{|c|c|c|c|c|c|c|c|c|c|c|c|c|c|c|}
\hline \multicolumn{15}{|c|}{ Return to scale of HEI from $2003-2009$} \\
\hline & \multicolumn{2}{|c|}{2003} & \multicolumn{2}{|c|}{2004} & \multicolumn{2}{|c|}{2005} & \multicolumn{2}{|c|}{2006} & \multicolumn{2}{|c|}{2007} & \multicolumn{2}{|c|}{2008} & \multicolumn{2}{|c|}{2009} \\
\hline & $\%$ & \# & $\%$ & \# & $\%$ & \# & $\%$ & \# & $\%$ & \# & $\%$ & \# & $\%$ & $\#$ \\
\hline CRS & 82.6 & 19 & 78.2 & 18 & 73.9 & 17 & 82.6 & 19 & 86.9 & 20 & 65.2 & 15 & 86.9 & 20 \\
\hline IRS & 8.70 & 3 & 13.04 & 3 & 17.3 & 4 & 4.35 & 1 & 8.70 & 2 & 17.3 & 4 & 0.00 & 0 \\
\hline DRS & 4.35 & 1 & 8.70 & 2 & 8.70 & 2 & 13.0 & 3 & 4.35 & 1 & 17.3 & 4 & 13.0 & 3 \\
\hline Total & 100 & 23 & 100 & 23 & 100 & 23 & 100 & 23 & 100 & 23 & 100 & 23 & 100 & 23 \\
\hline
\end{tabular}

RTS OF HEI 2003-2009

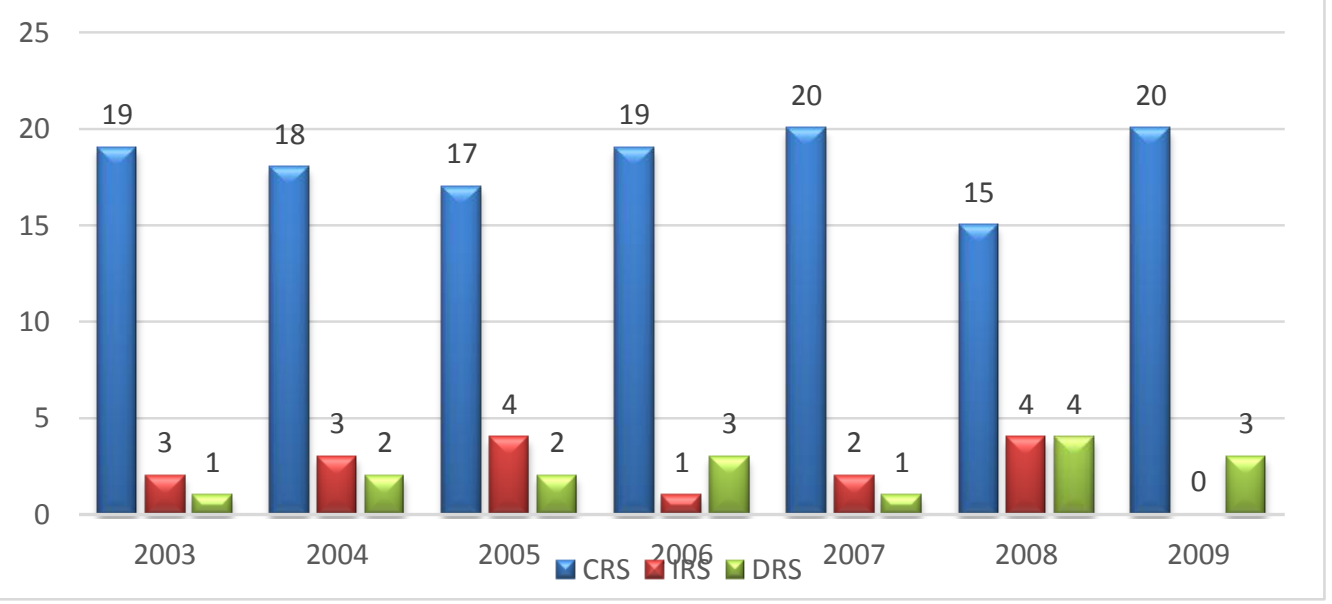

Figure.1 
Hina Fatima et al. "Technical Efficiency Analysis of Agricultural Research and Development in Higher Educational Institutes of Pakistan"

A VRS model disintegrates efficiency scores into pure and scale efficiency score. In order to examine whether the inefficiencies were because of increasing returns to scale (IRTS) or decreasing returns to scale (DRS), the VRS DEA model was run. The results designate that in year 2003, out of 23 HEI 19 (82.6\%) were operating at Constant Return to Scale (CRS) in other words in 200319 HEI were scale efficient. The result of the study further discloses that out of 23 HEI $3(8.7 \%)$ of institute operating at Increasing Return to Scale (IRS) and 1(4.35\%) institute working at Decreasing Return to Scale $(\mathrm{DRS})^{3}$.

The results of the study reveals that in year 2004, out of 23 HEI 18 (78.2\%) were operating at Constant Return to Scale (CRS) in other words in 2004, 18 HEI were scale efficient. The result of the study further discloses that out of $23 \mathrm{HEI} 3(13.4 \%)$ of institutes operating at Increasing Return to Scale (IRS) and $2(8.70 \%)$ institutes working at Decreasing Return to Scale(DRS).

The results of year 2005 shows that, out of 23 HEI 17 (73.9\%) were operating at Constant Return to Scale (CRS) in other words in 2005, 17 HEI were scale efficient. The result of the study further discloses that out of 23 HEI 4 (17.3\%) of institutes operating at Increasing Return to Scale (IRS) and $2(8.70 \%)$ institutes working at Decreasing Return to Scale(DRS).

The results of return to scale of year 2006 shows that, out of 23 HEI $19(82.6 \%)$ were operating at Constant Return to Scale (CRS) in other words in 2006,19 HEI were scale efficient. The result of the study further discloses that out of 23 HEI 1 (4.35\%) of institute operating at Increasing Return to Scale (IRS) and 3 (13.04\%) institutes working at Decreasing Return to Scale (DRS).

The results of year 2007 reveals that, out of 23 HEI 20 (86.9\%) were operating at Constant Return to Scale (CRS) in other words in 2007, 20 HEI were scale efficient. The result of the study further discloses that out of 23 HEI $2(8.7 . \%)$ institutes operating at Increasing Return to Scale (IRS) and 1 (4.35\%) institutes working at Decreasing Return to Scale (DRS).

The results of return to scale of year 2008 shows that, out of 23 HEI 15 (65.2\%) were operating at Constant Return to Scale (CRS) in other words in 2008, 15 HEI were scale efficient. The result of the study further discloses that out of 23 HEI 4 (17.3\%) of institute operating at Increasing Return to Scale (IRS) and 4 (17.3\%) institutes working at Decreasing Return to Scale(DRS).

The results of year 2009 reveals that, out of 23 HEI 20 (86.9\%) were operating at Constant Return to Scale (CRS) in other words in 2009, 20 HEI were scale efficient. The result of the study further discloses that out of 23 HEI $0(0.00 . \%)$ institutes operating at Increasing Return to Scale (IRS) and 3 $(13.04 \%)$ institutes working at Decreasing Return to Scale (DRS).

So the results of the study reveals that in case of IRS institutes an equivalent escalation in all inputs is result in more than a proportionate increase in outputs. So in order to upsurge the scale of operation there is need to increase in the demand as well. Those institutes operating at DRS, it means that that a percentage increase in all inputs is followed by less than a percentage change in outputs. So there is need to improve the efficiency of those HEI, in order to operate at optimal scale.

\section{CONCLUSION}

In this present study we have assess the efficiency of HEI that are functioning on agricultural research and development. Educational institute played a very important role in providing human capital and more advances techniques in agricultural sector through research and development. Pakistan being an agricultural developing country has to produce more output in all obedience of agriculture. By way of required revolutionize in the structure of the agricultural investment. The food price and economic crisis in 2008 have had a severe impact on majority of people in Pakistan. The solution to long-term food security lies in augmenting investment in agriculture research and development. DEA was used to estimate the technical and scale efficiency for the universities engaged agricultural research and Development. The technical and scale efficiency results suggests the agricultural universities in Pakistan are functioning at a fairly high level of efficiency, although there is room for improvement in several universities by improving the efficiency of those HEI, in order to operate at optimal scale.

\footnotetext{
${ }^{3}$ See Figure. 1
} 
Hina Fatima et al. "Technical Efficiency Analysis of Agricultural Research and Development in Higher Educational Institutes of Pakistan"

\section{REFERENCES}

[1] Abbott, M., Doucouliagos, C., (2002). The efficiency of Australian universities: A data envelopment analysis. Economics of Education Review 22 (1), 89-97.

[2] Banker, R.D. et al. (1984). Some models for estimating technical and scale inefficiencies in data envelopment analysis. Management Science 30, 1078-1092.

[3] Barro, R. J. (1991), Economic growth in a cross section of countries. Quarterly Journal of Economics, Volume 106(2), pp. 407-443.

[4] Barro, R. J. and X. Sala-i-Martin (1995), Economic Growth. New York: McGraw- Hill.

[5] Chatterji, M. (1998), Tertiary education and economic growth. Regional Studies, Volume 32(4), pp. 349-354.

[6] Chaudhary, A. R., I. Asim and S. Y. M. Gillani (2009), The nexus between higher education and economic growth: An empirical investigation for Pakistan. Pakistan Journal of Commerce and Social Sciences, Volume 3.

[7] Charnes, A., W.W. et al. (1978). Measuring the efficiency of decision making units. Euro. J. Ops. Res. 2: 429-444.

[8] C. T. Kuah, K. Y. Wong, and F. Behrouzi(2010), "A Review on Data Envelopment Analysis (DEA)". Fourth Asia International Conference on Mathematical/Analytical Modelling and Computer Simulation, 168-173.

[9] Coelli, T.J.(1995). Recent developments in frontier modeling and efficiency measurement. Australian Journal of Agricultural Economics. 39, 219-45.

[10] Coelli, T.J. (1996). A Guide to DEAP Version 2.1: A Data Envelopment Analysis (Computer) Program. CEPA Working Paper 96/08, Department of Econometrics, University of New England, Armidale.

[11] Coelli, T. et al (1998). An Introduction to Efficiency and Productivity Analysis. Kluwer, Boston.

[12] Ferrier, D. and Lovell C. A. K. (1990). Measuring Cost Efficiency in Banking, Econometric and Linear Programming Evidence. Journal of Econometrics, 1990; 46: 229-245.

[13] Farrell, M. (1957). The Measurement of Productivity Efficiency. Journal of the Royal Statistics Society, Series A, 120, 253-290.

[14] G. Fandel(2007), "On the Performance of Universities in North Rhine-Westphalia, Germany: Government's Redistribution of Funds Judged Using DEA Efficiency Measures". European Journal of Operational Research PP.521-533.

[15] Johnes, J. (2004). Efficiency measurement.In G. Johnes\& J. Johnes (Eds.), International handbook on the economics of education. Cheltenham: Edward Elgar.

[16] Johnes, J. (2006). DEA and its application to the measurement of efficiency in higher education".Economics of Education Review, 25(3), 273-288.

[17] Johnes, J. (2006). Measuring teaching efficiency in higher education: An application of data envelopment analysis to Economics graduates from UK universities. European Journal of Operational Research, 174, 443-456.

[18] Johnes, G., \&Johnes, J. (1993). Measuring the research performance UK economics departments: application of data envelopment analysis. Oxford Economic Papers, 45(2), 332348.

[19] Johnes, J., \& Johnes, G. (1995). Research funding and performance In UK. University departments of economics: a frontier analysis. Economics of Education Review, 14(3), 301-314.

[20] Johnes, G., \& Taylor, J. (1991).Performance indicators in higher education. Buckingham SRHE and Open University Press.

[21] Lee, M., B. Liu and P. Wang (1994). Education, human capital enhancement and economic development: Comparison between Korea and Taiwan. Economics of Education Review, Volume 13(4), pp. 275-288.

[22] M. L. Bougnol and J. Dula(2006), Validating DEA as a Ranking Tool: An Application of DEA to Assess Performance in Higher Education. Annals of Operations Research PP.339-365.

[23] Murillo-Zamorano and Luis, R. (2004). Economic efficiency and frontier techniques. Journal of 
Hina Fatima et al. "Technical Efficiency Analysis of Agricultural Research and Development in Higher Educational Institutes of Pakistan"

Economic Surveys, 18 (1): 33-77.

[24] Sharma, S. and Thomas, V.J (2008). Inter-country R\&D efficiency analysis: An application of data envelopment analysis. Scientometrics, 76 (3), pp. 483-501.

[25] Romer, P. (1987), Endogenous technical change. Journal of Political Economy, Volume 89, pp. 71-102.

\section{APPENDIX}

Table1

\begin{tabular}{|c|c|c|c|c|c|c|c|c|c|c|c|c|}
\hline \multirow[t]{2}{*}{ Year } & \multicolumn{3}{|c|}{ Enrolled Students } & \multicolumn{6}{|c|}{ UNIVERSITY STAFF } & \multicolumn{3}{|c|}{ Graduated Students } \\
\hline & PhDs & MS & MSC/BS & PhDs & MA & MSC & ADMIN & TECHNICIANS & $\begin{array}{l}\text { OTHER } \\
\text { STAFF }\end{array}$ & PhDs & MS & MSC/BS \\
\hline \multicolumn{13}{|c|}{2003} \\
\hline Sum & 2447 & 8025 & 18461 & 834 & 690 & 565 & 463 & 84 & 1893 & 203 & 5825 & 15436 \\
\hline Mean & 106 & 349 & 879.1 & 36.3 & 31.4 & 24.6 & 21.0 & 3.8 & 82.3 & 8.8 & 253.3 & 701.6 \\
\hline SD & 241 & 730 & 2107.7 & 57.6 & 54.7 & 79.8 & 38.2 & 5.6 & 215.5 & 24.0 & 555.8 & 1934.2 \\
\hline Maximum & 1001 & 2310 & 9570 & 208 & 219 & 294 & 170 & 24 & 1035 & 115 & 2212 & 8966 \\
\hline Minimum & 0 & 0 & 0 & 0 & 0 & 0 & 0 & 0 & 0 & 0 & 0 & 0 \\
\hline $\begin{array}{l}\text { Percentage } \\
\text { change }\end{array}$ & 17.0 & 10.1 & 10.0 & 11.8 & 10.9 & 15.0 & 6.2 & 2.4 & 9.6 & 2.9 & 10.4 & 11.9 \\
\hline \multicolumn{13}{|c|}{2004} \\
\hline Sum & 1852 & 11528 & 20464 & 864 & 740 & 430 & 899 & 100 & 2358 & 261 & 6182 & 18440 \\
\hline Mean & 84.2 & 501.2 & 930.2 & 37.6 & 33.6 & 18.7 & 39.1 & 4.3 & 102.5 & 12.4 & 268.8 & 801.7 \\
\hline SD & 136.9 & 1036 & 2305.0 & 58.3 & 57.4 & 64.0 & 76.6 & 7.1 & 224.6 & 32.6 & 558.4 & 2311.7 \\
\hline Maximum & 546 & 3959 & 10735 & 231 & 228 & 280 & 329 & 31 & 1028 & 150 & 2214 & 11000 \\
\hline Minimum & 0 & 0 & 0 & 0 & 0 & 0 & 0 & 0 & 0 & 0 & 0 & 0 \\
\hline $\begin{array}{l}\text { Percentage } \\
\text { change }\end{array}$ & 12.8 & 14.5 & 11.1 & 12.2 & 11.7 & 11.4 & 12.0 & 2.8 & 12.0 & 3.7 & 11.0 & 14.2 \\
\hline \multicolumn{13}{|c|}{2005} \\
\hline Sum & 1627 & 8722 & 23569 & 919 & 778 & 460 & 919 & 1349 & 1411 & 310 & 9259 & 17121 \\
\hline Mean & 74.0 & 379.2 & 1024.7 & 41.8 & 35.4 & 20.0 & 40.0 & 58.7 & 61.3 & 13.5 & 402.6 & 778.2 \\
\hline SD & 116.4 & 642.1 & 2571.4 & 65.4 & 57.5 & 68.5 & 72.2 & 257.9 & 104.2 & 41.4 & 1003 & 1973.2 \\
\hline Maximum & 494 & 2178 & 12191 & 255 & 221 & 300 & 312 & 1241 & 432 & 200 & 3877 & 9000 \\
\hline Minimum & 0 & 0 & 0 & 0 & 0 & 0 & 0 & 0 & 0 & 0 & 0 & 0 \\
\hline $\begin{array}{l}\text { Percentage } \\
\text { change }\end{array}$ & 11.3 & 11.0 & 12.8 & 13.0 & 12.3 & 12.2 & 12.3 & 38.2 & 7.2 & 4.4 & 16.5 & 13.2 \\
\hline \multicolumn{13}{|c|}{2006} \\
\hline Sum & 1988 & 9094 & 23832 & 987 & 877 & 519 & 1046 & 131 & 2779 & 249 & 7002 & 16911 \\
\hline Mean & 86.4 & 395.4 & 1083.3 & 42.9 & 39.9 & 23.6 & 45.5 & 5.7 & 120.8 & 10.8 & 304.4 & 768.7 \\
\hline SD & 178.1 & 747.1 & 2428.4 & 68.0 & 62.4 & 77.0 & 81.8 & 9.2 & 271.5 & 31.3 & 663.2 & 1824.7 \\
\hline Maximum & 738 & 2912 & 11050 & 268 & 233 & 320 & 344 & 42 & 1251 & 150 & 2730 & 8000 \\
\hline Minimum & 0 & 1 & 0 & 0 & 0 & 0 & 0 & 0 & 0 & 0 & 0 & 0 \\
\hline $\begin{array}{l}\text { Percentage } \\
\text { change }\end{array}$ & 13.8 & 11.5 & 12.9 & 13.9 & 13.8 & 13.8 & 14.0 & 3.7 & 14.1 & 3.5 & 12.5 & 13.1 \\
\hline \multicolumn{13}{|c|}{2007} \\
\hline Sum & 2743 & 18829 & 27064 & 1071 & 932 & 591 & 1285 & 1500 & 2613 & 440 & 8676 & 21561 \\
\hline Mean & 124.7 & 818.7 & 1288.8 & 46.6 & 42.4 & 25.7 & 55.9 & 65.2 & 113.6 & 20.0 & 377.2 & 1026.7 \\
\hline \begin{tabular}{|l|} 
SD \\
\end{tabular} & 238.5 & 1847.7 & 2654.4 & 71.1 & 63.5 & 84.1 & 100.8 & 280.9 & 234.7 & 74.0 & 801.4 & 2326.9 \\
\hline Maximum & 848 & 7231 & 11754 & 283 & 229 & 340 & 419 & 1353 & 978 & 350 & 3411 & 10000 \\
\hline Minimum & 0 & 1 & 0 & 0 & 0 & 0 & 0 & 0 & 0 & 0 & 0 & 0 \\
\hline $\begin{array}{l}\text { Percentage } \\
\text { change }\end{array}$ & 19.0 & 23.7 & 14.6 & 15.1 & 14.7 & 15.7 & 17.2 & 42.4 & 13.3 & 6.3 & 15.5 & 16.6 \\
\hline \multicolumn{13}{|c|}{2008} \\
\hline Sum & 1637 & 8357 & 40638 & 1171 & 1126 & 590 & 1357 & 170 & 3429 & 5107 & 14617 & 22874 \\
\hline Mean & 71.2 & 363.3 & 1847.2 & 50.9 & 51.2 & 25.7 & 59.0 & 7.4 & 149.1 & 222.0 & 635.5 & 1089.2 \\
\hline SD & 119.9 & 693.3 & 3504.3 & 79.5 & 74.8 & 84.4 & 106.7 & 11.9 & 320.8 & 1042 & 1678 & 2699.0 \\
\hline Maximum & 433 & 2902 & 11835 & 311 & 259 & 350 & 443 & 54 & 1446 & 5000 & 6293 & 9932 \\
\hline Minimum & 0 & 0 & 0 & 0 & 0 & 0 & 0 & 0 & 0 & 0 & 3 & 0 \\
\hline $\begin{array}{l}\text { Percentage } \\
\text { change }\end{array}$ & 11.3 & 10.5 & 22.0 & 16.5 & 17.7 & 15.6 & 18.2 & 4.8 & 17.4 & 72.7 & 26.1 & 17.7 \\
\hline \multicolumn{13}{|c|}{2009} \\
\hline Sum & 2141 & 14732 & 30819 & 1243 & 1202 & 615 & 1504 & 200 & 5200 & 452 & 4517 & 17159 \\
\hline Mean & 93.1 & 640.5 & 1467.6 & 54.0 & 54.6 & 26.7 & 65.4 & 8.7 & 226.1 & 19.7 & 196.4 & 858.0 \\
\hline SD & 158.9 & 1283 & 2517.1 & 82.4 & 80.4 & 87.3 & 107.5 & 13.0 & 427.1 & 62.4 & 329.9 & 1514.7 \\
\hline Maximum & 548 & 4892 & 10205 & 310 & 259 & 358 & 444 & 56 & 1461 & 303 & 1075 & 4935 \\
\hline Minimum & 0 & 0 & 0 & 0.01 & 0 & 0 & 0 & 0 & 0 & 0 & 0 & 0 \\
\hline $\begin{array}{l}\text { Percentage } \\
\text { change }\end{array}$ & 14.8 & 18.6 & 16.7 & 17.5 & 18.9 & 16.3 & 20.1 & 5.7 & 26.4 & 6.4 & 8.1 & 13.2 \\
\hline
\end{tabular}

Source: self calculation and estimation 
Hina Fatima et al. "Technical Efficiency Analysis of Agricultural Research and Development in Higher Educational Institutes of Pakistan"

Table2. Technical Efficiency of (HEC) Institutes in Agriculture (R\&D) in 2003

\begin{tabular}{|c|c|c|c|}
\hline INSTITUTES & CRSTE & VRSTE & SE \\
\hline 1 & 1 & 1 & 1 \\
\hline 2 & 1 & 1 & 1 \\
\hline 3 & 1 & 1 & 1 \\
\hline 4 & 1 & 1 & 1 \\
\hline 5 & 1 & 1 & 1 \\
\hline 6 & 1 & 1 & 1 \\
\hline 7 & 0.727 & 0.728 & 0.999 \\
\hline 8 & 1 & 1 & 1 \\
\hline 9 & 1 & 1 & 1 \\
\hline 10 & 0.252 & 1 & 0.252 \\
\hline 11 & 0.705 & 1 & 0.705 \\
\hline 12 & 1 & 1 & 1 \\
\hline 13 & 1 & 1 & 1 \\
\hline 14 & 0.763 & 0.763 & 1 \\
\hline 15 & 1 & 1 & 1 \\
\hline 16 & 0.703 & 1 & 0.703 \\
\hline 17 & 1 & 1 & 1 \\
\hline 18 & 1 & 1 & 1 \\
\hline 19 & 1 & 1 & 1 \\
\hline 20 & 1 & 1 & 1 \\
\hline 21 & 0.539 & 1 & 0.539 \\
\hline 22 & 1 & 1 & 1 \\
\hline 23 & 1 & 1 & 1 \\
\hline
\end{tabular}

Table3. Technical Efficiency of (HEC) Institutes in Agriculture (R\&D) in 2004

\begin{tabular}{|c|c|c|c|}
\hline INSTITUTES & CRSTE & VRSTE & SE \\
\hline 1 & 1 & 1 & 1 \\
\hline 2 & 1 & 1 & 1 \\
\hline 3 & 1 & 1 & 1 \\
\hline 4 & 0.749 & 1 & 1 \\
\hline 5 & 1 & 1 & 1 \\
\hline 6 & 1 & 1 & 1 \\
\hline 7 & 1 & 1 & 1 \\
\hline 8 & 1 & 1 & 1 \\
\hline 9 & 1 & 1 & 0.93 \\
\hline 10 & 0.93 & 1 & 1 \\
\hline 11 & 1 & 1 & 1 \\
\hline 12 & 1 & 1 & 1 \\
\hline 13 & 1 & 0.792 & 0.95 \\
\hline 14 & 0.792 & 1 & 1 \\
\hline 15 & 0.95 & 1 & 1 \\
\hline 16 & 1 & 1 & 1 \\
\hline 17 & 1 & 1 & 1 \\
\hline 18 & 1 & 1 & 0.843 \\
\hline 19 & 0.543 & 1 & 1 \\
\hline 20 & 1 & 0.551 & 1 \\
\hline 21 & 0.465 & 1 & \\
\hline 22 & 1 & & 1 \\
\hline 23 & 1 & 1 & 1 \\
\hline
\end{tabular}

Source: self calculation and estimation 
Hina Fatima et al. "Technical Efficiency Analysis of Agricultural Research and Development in Higher Educational Institutes of Pakistan"

Table4. Technical Efficiency of (HEC) Institutes in Agriculture $(R \& D)$ in 2005

\begin{tabular}{|c|c|c|c|}
\hline INSTITUTES & CRSTE & VRSTE & SE \\
\hline 1 & 1 & 1 & 1 \\
\hline 2 & 1 & 1 & 1 \\
\hline 3 & 1 & 1 & 0.799 \\
\hline 4 & 0.799 & 1 & 1 \\
\hline 5 & 1 & 1 & 1 \\
\hline 6 & 1 & 1 & 1 \\
\hline 7 & 1 & 1 & 0.837 \\
\hline 8 & 1 & 1 & 0.996 \\
\hline 9 & 0.837 & 0.963 & 1 \\
\hline 10 & 0.959 & 1 & 1 \\
\hline 11 & 1 & 1 & 0.942 \\
\hline 12 & 1 & 1 & 1 \\
\hline 13 & 1 & 0.737 & 1 \\
\hline 14 & 0.694 & 1 & 1 \\
\hline 15 & 1 & 1 & 1 \\
\hline 16 & 1 & 1 & 0.443 \\
\hline 17 & 1 & 1 & 1 \\
\hline 18 & 1 & 1 & 0.557 \\
\hline 19 & 0.443 & 1 & 1 \\
\hline 20 & 1 & 1 & 1 \\
\hline 21 & 0.557 & 1 & \\
\hline 23 & 1 & 1 & \\
\hline & 1 & 1 & \\
\hline & & 1 & \\
\hline & & 1 & 1 \\
\hline
\end{tabular}

Source: self calculation and estimation

Table5. Technical Efficiency of (HEC) Institutes in Agriculture (R\&D) in 2006

\begin{tabular}{|c|c|c|c|}
\hline INSTITUES & CRSTE & VRSTE & SE \\
\hline 1 & 1 & 1 & 1 \\
\hline 2 & 1 & 1 & 1 \\
\hline 3 & 1 & 1 & 1 \\
\hline 4 & 1 & 1 & 1 \\
\hline 5 & 1 & 1 & 1 \\
\hline 6 & 1 & 1 & 1 \\
\hline 7 & 1 & 1 & 1 \\
\hline 8 & 1 & 1 & 1 \\
\hline 9 & 1 & 1 & 1 \\
\hline 10 & 1 & 1 & 1 \\
\hline 11 & 1 & 1 & 0.977 \\
\hline 12 & 1 & 0.851 & 0.907 \\
\hline 13 & 1 & 1 & 0.829 \\
\hline 14 & 0.831 & 1 & 1 \\
\hline 15 & 0.907 & 1 & 1 \\
\hline 16 & 0.829 & 1 & 1 \\
\hline 17 & 1 & 1 & 1 \\
\hline 18 & 1 & 1 & 0.789 \\
\hline 19 & 1 & 0.503 & 1 \\
\hline 20 & 1 & 1 & 1 \\
\hline 21 & 0.397 & 1 & \\
\hline 22 & 1 & & \\
\hline 23 & 1 & 1 & \\
\hline & & 1 & \\
\hline & & 1 & 1 \\
\hline
\end{tabular}

Source: self calculation and estimation

Table6. Technical Efficiency of (HEC) Institutes in Agriculture (R\&D) in 2007

\begin{tabular}{|c|c|c|c|}
\hline INSTITUTES & CRSTE & VRSTE & SE \\
\hline 1 & 1 & 1 & 1 \\
\hline 2 & 1 & 1 & 1 \\
\hline 3 & 1 & 1 & 1 \\
\hline
\end{tabular}


Hina Fatima et al. "Technical Efficiency Analysis of Agricultural Research and Development in Higher Educational Institutes of Pakistan"

\begin{tabular}{|c|c|c|c|}
\hline 4 & 0.721 & 0.734 & 0.982 \\
\hline 5 & 1 & 1 & 1 \\
\hline 6 & 1 & 0.902 & 0.914 \\
\hline 7 & 0.825 & 1 & 1 \\
\hline 8 & 1 & 1 & 1 \\
\hline 9 & 1 & 1 & 1 \\
\hline 10 & 1 & 1 & 1 \\
\hline 11 & 1 & 1 & 1 \\
\hline 12 & 1 & 1 & 1 \\
\hline 13 & 1 & 1 & 1 \\
\hline 14 & 1 & 1 & 1 \\
\hline 15 & 1 & 1 & 1 \\
\hline 16 & 1 & 1 & 1 \\
\hline 17 & 1 & 1 & 1 \\
\hline 19 & 1 & 1 & 0.678 \\
\hline 20 & 1 & 1 & 1 \\
\hline 21 & 1 & 1 & 1 \\
\hline 22 & 0.678 & 1 & \\
\hline 23 & 1 & 1 & \\
\hline
\end{tabular}

Source: self calculation and estimation

Table7. Technical Efficiency of (HEC) Institutes in Agriculture $(R \& D)$ in 2008

\begin{tabular}{|c|c|c|c|}
\hline INSTITUES & CRSTE & VRSTE & SE \\
\hline 1 & 1 & 1 & 1 \\
\hline 2 & 1 & 1 & 1 \\
\hline 3 & 1 & 1 & 1 \\
\hline 4 & 1 & 1 & 1 \\
\hline 5 & 1 & 1 & 0.53 \\
\hline 6 & 1 & 1 & 0.7 \\
\hline 7 & 0.53 & 1 & 1 \\
\hline 8 & 0.7 & 1 & 1 \\
\hline 9 & 1 & 0.951 & 0.996 \\
\hline 10 & 1 & 1 & 1 \\
\hline 11 & 0.948 & 1 & 0.98 \\
\hline 12 & 1 & 0.481 & 0.853 \\
\hline 13 & 1 & 1 & 0.598 \\
\hline 14 & 0.472 & 1 & 1 \\
\hline 15 & 0.853 & 1 & 1 \\
\hline 16 & 0.598 & 1 & 0.329 \\
\hline 17 & 1 & 1 & 1 \\
\hline 18 & 1 & 1 & 0.73 \\
\hline 20 & 0.329 & 1 & 1 \\
\hline 21 & 1 & 1 & 1 \\
\hline 22 & 0.73 & 1 & \\
\hline 23 & 1 & 1 & 1 \\
\hline
\end{tabular}

Source: self calculation and estimation

Table8. Technical Efficiency of (HEC) Institutes in Agriculture (R\&D) in 2009

\begin{tabular}{|c|c|c|c|}
\hline INSTITUTES & CRSTE & VRSTE & SE \\
\hline 1 & 1 & 1 & 1 \\
\hline 2 & 1 & 1 & 1 \\
\hline 3 & 1 & 1 & 1 \\
\hline 4 & 1 & 1 & 1 \\
\hline 5 & 1 & 1 & 1 \\
\hline 6 & 1 & 1 & 1 \\
\hline 7 & 0.608 & 0.608 & 1 \\
\hline 8 & 0.746 & 0.746 & \\
\hline
\end{tabular}


Hina Fatima et al. "Technical Efficiency Analysis of Agricultural Research and Development in Higher Educational Institutes of Pakistan"

\begin{tabular}{|c|c|c|c|}
\hline 9 & 1 & 1 & 1 \\
\hline 10 & 1 & 1 & 1 \\
\hline 11 & 1 & 1 & 1 \\
\hline 12 & 1 & 1 & 1 \\
\hline 13 & 1 & 0.906 & 0.826 \\
\hline 14 & 0.748 & 1 & 0.856 \\
\hline 15 & 0.856 & 1 & 1 \\
\hline 16 & 1 & 1 & 1 \\
\hline 17 & 1 & 1 & 1 \\
\hline 18 & 1 & 0.574 & 0.717 \\
\hline 20 & 0.574 & 1 & 1 \\
\hline 21 & 1 & 0.533 & 1 \\
\hline 22 & 0.382 & 0.818 & \\
\hline 23 & 0.818 & 1 & \\
\hline
\end{tabular}

Source: self calculation and estimation

\begin{tabular}{|l|}
\hline \multicolumn{1}{|c|}{ Institutes } \\
\hline Sindh Agriculture University, Tandojam, Pakistan \\
\hline Pir Mehr Ali Shah Arid Agriculture University Rawalpindi \\
\hline Gomel University and Faculty of Agriculture \\
\hline University of Veterinary and Animal Sciences \\
\hline University of Veterinary and Animal Sciences, Lahore \\
\hline University of Veterinary and Animal Sciences, Lahore (Department of Livestock Production) \\
\hline Faculty of Animal Husbandry, University of Agriculture, Faisalabad. \\
\hline Division of Agriculture and Extension, University of Agriculture, Faisalabad. \\
\hline $\begin{array}{l}\text { Faculty of crop sciences, Department of Food Technology,Pir Mehr Ali Shah University of Arid Agriculture } \\
\text { Rawalpindi }\end{array}$ \\
\hline Faculty of Agricultural Economics and Rural Sociology, University of Agriculture, Faisalabad. \\
\hline Faculty of Agricultural Economics and Rural Sociology, University of Agriculture, Faisalabad. \\
\hline Faculty of Agriculture, University of Agriculture Faisalabad, Jail Road \\
\hline Faculty of Sciences, University of Agriculture, Faisalabad \\
\hline Faculty of Veterinary Science, University of Agriculture Faisalabad. \\
\hline Vice Chancellor Office, University of Agriculture, Faisalabad \\
\hline Department of Agriculture Sciences,Allama Iqbal open university Islamabad, Pakistan \\
\hline Faculty of Biological Sciences Quaid-i-Azam University Islamabad \\
\hline Institute of Environmental and Engineering and Management \\
\hline PMAS Arid Agriculture University Rawalpindi. \\
\hline Punjab University Lahore \\
\hline University of Engineering \& Technology, Lahore \\
\hline Department of Fresh Water Biology and Fisheries, University of Sindh \\
\hline Institute of Water Resources and Management, Mehran University of Engineering \& Technology, Jamshoro \\
\hline
\end{tabular}

